\title{
Laboratory Experimental Testbeds: Application to the PCS Auction
}

\author{
Charles R. Plott \\ California Institute of Technology \\ Pasadena, CA 91125 \\ cplott@hss.caltech.edu
}

The paper reviews the uses of laboratory experimental economics methods in the background research and implementation of the Personal Communication Systems auctions held by the Federal Communications Commission. The applications began during the rule making process with the testing of broad rules that might be implemented. Data from experiments were systematically used. The methods were used again in the software development process where several important contributions were made. Finally, experiences gained from the study of experimental auction processes were used in the actual management of the first auctions and in interpreting auction performance.

\section{Introduction}

The use of laboratory experimental methods in economics has been growing rapidly. With each application, new insights are gained into how the methodology can be used to supplement the more traditional forms of research. Such was the case with the development of the Federal Communications Commission (FCC) policy for the auction of licenses for personal communication systems (PCS). At several different stages the laboratory experimental methods of economics were used. The application differed at each of these stages, representing the different types of relationships that can exist among theory, observation, and policy. This paper is a brief account of the applications.

The use of laboratory experimental data began only after many major decisions had been made by the FCC. The big questions whether or not there should be an auction, what was to be auctioned, and when the auctions were to take place had all been answered. The government had decided that an auction mechanism should be used in place of the classical, administered methods of granting broadcast licenses. The

(C) 1997 Massachusetts Institute of Technology.

Journal of Economics \& Management Strategy, Volume 6, Number 3, Fall 1997, 605-638 
structure of the licenses had been determined, and the time frame and sequences of auctions had been determined.

Wisely, the government separated the decision about the rules that were going to govern the auction from the other decisions. An independent rulemaking process was used to decide what the rules of the auction should be. The FCC's rulemaking process took place in fall of 1993. Decisions were made in the winter and spring of 1994. The first auction of nine (nationwide narrowband) PCS licenses took place in July 1994, and it was followed by the auction of thirty regional narrowband PCS licenses in the fall of 1994. In addition the FCC conducted an auction of licenses for interactive video data services (IVDS) in July 1994.

By the fall of 1993 the business world was fully aware of the rulemaking process and had engaged many groups of consultants to help them position themselves. Businesses understood that the rules and form of the auction could influence who acquired what and how much was paid. The rules of the auction could be used to provide advantages to themselves or to their competitors. Thus, a mixture of self-interest and fear motivated many different and competing architectures for the auctions as different businesses promoted different rules. The position of the FCC was that the efficient allocation of the licenses was to be the primary criterion for deciding among the competing options. The criterion was not to maximize revenue, and it was not to simply mimic historically accepted methods of conducting auctions. This attitude of the FCC colored the whole rulemaking process, shaped the debates, and generally influenced the character of the rules that were proposed. The efficiency criterion and the openness to new types of auctions also opened the door for experimental methods. As will be outlined in the pages that follow, the experimental methodology provides a noncontroversial, inexpensive, and fast method for getting data on how various types of auctions might perform. While experiments could not remove all controversy, they could at least remove part of it.

The first experiments were conducted in the fall of 1993. In January 1994 a conference was held at Caltech in which much experimental data were reviewed. A group of Caltech experimentalists were hired in the spring of 1994 to help test rules and to help with the actual implementation of the auctions. That relationship lasted through the fall of 1994 and the regional narrowband auctions of thirty licenses. After that the FCC had its own software, procedures, auction team, and experience. The report that follows describes what was done and what was learned during that year of auction decisions and development. 


\section{Laboratory Methods}

Perhaps, before discussing the FCC auctions, it would be instructive to provide a word or two on the nature of experimental economics as applied to the study of auctions. The basic idea is to use substantial financial incentives to create simple and well-controlled auction processes. The methods are used to study a wide variety of decision processes, so it is possible to compare behavior of many different people in many different contexts. The people engaging in the auctions make money that is theirs to keep. The characteristics of the people, the nature of the incentives, the rules of the auctions, what people are told, etc., are all carefully considered and may differ among experiments, depending upon the purpose and what one wants to know. The experimental procedures, like the ones employed in the experiments reported here, are exactly the same as ones that have been subjected to thousands of studies. The results of the experiments are compared internally against theory and other types of experiments, so confidence is built that the results are not due to some sort of special or isolated feature.

The general idea of a laboratory experiment is to study the operation of rules, such as auction rules, in very simple cases. The simplicity assures that the nature of any problems detected can be identified and studied. The variables studied reflect human behavior in the use of the rules, the relationship of behavior to the technology used to implement the rules of the auction, and the reliability of the technology itself. An experimental testbed is a simple working prototype of a process that is going to be employed in a complex environment. The creation of the prototype and the study of its operation provides a joining of theory, observation, and the practical aspects of implementation.

Two questions are posed. The first is: does the auction work, in the sense that it produces outcomes and efficiencies that are generally acceptable? The second question is does the auction operate according to the theory that led to its creation? If a mechanism does not work acceptably in a simple case created in a laboratory, then there may be no reason to think that it will work in the complex cases found in a field application. Such failures are viewed as a failure of proof of concept. However, even if a mechanism passes a proof of concept, it might have done so for accidental reasons. Unless the performance is reasonably consistent with theory, unless the mechanism works for understandable reasons, then again, there may be no reason to think that it would work in complex field applications. The second question reflects a requirement that a mechanism meet a test of design consistency. 


\section{An Overview and the Context of Applications}

The most intense use of experimental methods in the FCC applications occurred at three different stages of the policymaking process. At each of these stages natural research partnerships could be identified. Initially, the experimental research was focused on broad aspects of the rules that might be put in place. This was the first stage of testbedding, as the properties of substantially different types of rules were examined. The second stage of testbedding evolved as the rules began to take a more definite form. The study shifted to detailed features of particular rules and was then expanded to include assessments of the operational form of specific rules as they were implemented in the software. Rules, stated as policy, can be very different when they are put in operational form as procedures and software. Simple laboratory environments provide an inexpensive method of discovering practical problems with the rules, as they are found in the real software setting, that could prove to be very expensive if they surfaced during the operation of a multibillion-dollar auction. Thus, at this stage, the experimental methods were, in a sense, part of debugging. The final stage of application occurred during the actual operation of the auction. Theory, modified by experience in use, is very useful when attempting to make decisions in rapidly changing circumstances. The observations from experiments were used as a source of judgment about events that were taking place during the auctions and the possible implications of changing features of the auction ("improvements") as the auction was taking place. The paper addresses decisions that were made during the auctions and how they were influenced by experiments.

The final rules used by the FCC had several key elements. First, the rules were implemented electronically with decentralized bidders. Second, a separate market was opened for each license. The FCC had reason to think that complementarities existed among licenses. In some cases the value of a license depended upon the other licenses held, so bidders wanted to commit to buy simultaneously. All markets were open simultaneously. Third, the markets proceeded in "rounds" of bidding. Within a round, bids were submitted for all licenses. Fourth, activity rules were in place. These rules were used to force bidders to bid rather than waiting to see how others bid before submitting their own bids. The activity rules imposed requirements on the number of items on which a bidder could bid. If the bidder failed to bid (unless the bidder was the high bidder), then the right to bid in future rounds could be reduced. The auctions had different stages in which different activity rules were imposed, and these rules became more stringent in later stages when the FCC might be attempting to get the markets to 
close. Finally, the auction had a withdrawal option. Suppose a bidder valued packages or groups of licenses and that the value fell sharply if any member of the package was missing. A bidder who held part of a package and felt that the other parts would be too expensive could withdraw from the licenses held, letting the price fall to the lowest past bid. If the final price was less than the bid of the withdrawing bidder, then the bidder paid the difference. In addition, the auction had waiver features that allowed bidders to skip rounds a limited number of times without the penalty imposed by activity rules and thereby allow time to assess complicated bidding strategies or seek additional financing.

\section{Research On Rules: The First Stage}

The first stage focused on the rules of the auction and the consequent behavior that might be expected under various conditions. Different rules can induce different patterns of outcomes in terms of efficiency and distribution, depending upon the underlying economic conditions. Much of the theory that existed at the time of the design of the auction was incomplete and untested. No single theory existed about which there was a consensus. The first stage of experimental work was thus closely connected to the development of theory and a sensitivity to the differences of opinions that existed among theorists.

Research during this first stage was difficult. The rules were not determined. Up to and even during the actual auction, the rules were constantly and rapidly evolving. By practical necessity, and because of the need for information, the experiments typically addressed a feature of the rules, or features of classes of rules, as opposed to fully testing some well-defined set of rules and procedures. Furthermore, because of time constraints, decisions had to be made on very small numbers of observations. The environment in which the actual auctions would take place was similarly uncertain. It was assumed that the items auctioned involved complementarities, and that a large number of participants would be bidding. But, the full implications of these assumptions were never fully explored. Similarly, many relevant environments were not studied at all. For example, while it is well established experimentally that uncertain common values of the items auctioned can result in a winner's curse, the special problems that might surface for FCC rules in common-value environments were not pursued. Time and resource constraints prevented the study of many interesting and important problems.

Testimony during the FCC decisionmaking process provided a 
focus for early experiments. Three major issues that surfaced in the testimony were chosen for experimental examination. The first issue was whether the auction would be one of the forms commonly implemented by professional auction houses, such as oral auctions, or would be something completely new. In part, this first issue seemed to turn on whether it was technologically feasible to do something new and completely different from the time-tested methods of auctioning things. The second issue was focused more narrowly on the definitions and characteristics of particular classes of rules: whether the licenses should be sold sequentially or simultaneously. The third issue was similarly focused on the details of the rules, and the type of behavior that might be observed under different rules. As will be discussed, this third issue was closely associated with the economic environments that might exist for the FCC auctions. The expected behavior can depend dramatically upon the environmental features present. The research focused on rules that might be able to operate in troublesome environments.

\subsection{Something Old or Something New}

The most commonly used auction rules, as implemented by professional auction houses, are sealed bids and oral, ascending-bid auctions in which items are sold sequentially. Experimental research suggested that sealed-bid auctions would not function as desired. Almost all experimental work suggests that some sort of iteration is necessary for processes to have the efficiency and price-discovery properties suggested by pure theory. Equilibration (and thus disequilibrium) seems to be a fact of life. While no experimental work was conducted to explore this particular issue, many experimental sealed-bid auctions have been conducted, and that literature was used for reference.

One early issue was whether the classical oral auction should be used, as opposed to a more technologically oriented process. Some voices in the FCC were skeptical of the advisability of using new technologies that had no track record in the field. The question was whether or not people could operate in the type of technological environment characteristic of new types of processes that were being suggested by theory. The fear was that the behavioral/cognitive demands required by the processes would render them infeasible.

These early issues were brought into focus at a meeting held at the California Institute of Technology in January of 1994. Experimentalists addressed this issue directly by demonstrating the operation of decentralized electronic auction processes. Computerized auctions have been operating for years in laboratories, where they have been used in experiments. Laboratory experiments have demonstrated conclusively that 
people are generally capable of dealing with the "technologically intensive" processes that are applied in modern electronic and computerized auctions. They have also demonstrated that the necessary software and hardware exist in operational form and can be made reliable. Thus, at the Caltech conference, the operation of new processes, based on electronic technology, was demonstrated.

In addition, conference presentations were made by the Pacific Stock Exchange and other parties familiar with the operations of electronic and computerized market processes. Thus, while the issue of the tried and true against something new continued to be raised in some in the debates, experimental data existed that could be used as an answer to those concerned about the issue and, in some respects, clearly demonstrated that the problem of information and cognitive limitations of people would not be an insurmountable obstacle to the implementation of new types of auctions. It also became clear that technology was not an obstacle. The consensus developed that new rules could be used, and the discussion moved to consider the forms that they might take.

\subsection{Simultaneous Auctions vs. Sequential Japanese Auctions with a Package Bid}

Very early on the discussions became narrowed to two different auction architectures. These two competing architectures were the focus of many of the early experiments. The experiments were designed to inquire about the properties of simultaneous auctions in comparison with sequential auctions that are accompanied by bids on predetermined packages. In the latter architecture, a specific set of items would be offered for sale, either as a package or individually. Sealed bids would be tendered for the package. The winning bid for the package would be announced. After the announcement, the markets for individual items would be opened and the items would then be individually auctioned. Whether the sale was made by package of items to the winning sealed bid, or by individual items to the winners of the individual-item markets, was to be determined by which would generate the most money. The details of the institutions studied are as follows:

\subsubsection{Simultaneous, Continuous, Ascending-Price} Auctions for All Items (With and Without Rel ease-toMar ket Provision). Within this set of rules, each license would be identified in a separate market. All markets would be open simultaneously. Bids could be tendered at any time the bidder desired. An accepted bid must be higher than the existing bid. All markets would close at the same time, when no market had received a bid for some 
predetermined period of time. That is, if no bids were tendered in any market for a set period, then all markets would close simultaneously; but if a bid occurred in any market, then all markets would remain open for at least the predetermined period.

The method of ending the auction is very important and figures heavily in the rules finally adopted by the FCC. The FCC auctions were not continuous, but instead proceeded in rounds. In a continuous market, the continuous threat of the end serves to force bidders into action. If there is no action, then the markets close, and the faster the bidding, the sooner the auction will be over. The introduction of rounds gives bidders an incentive to wait. Thus, the FCC adopted activity rules and rules governing eligibility that are not part of the earliest experiments.

The release-to-market provision (withdrawal) gave bidders an opportunity to withdraw from units on which they had the high bid. If a unit is released to the market by a bidder, then the bid price is dropped and the bidding can then start from the lower level. The bidder who withdrew from the item would pay the FCC the difference between the bidder's bid and the final bid at which the item sold. The idea is that a bidder who failed to get a package would be able to sell the partial package already acquired back to the market. Reselling during the auction, as opposed to after the auction closed, might be advantageous because during the auction the demand might be expected to be strong due to the assembled buyers at the auction.

4.2.2 Sequential, Continuous Auctions with a Seal ed Bid for Packages of Predesignated Collections of

It ems. Under this proposal, the sealed bids would be opened prior to the opening of the markets in which individual items would be auctioned. Two different possibilities existed to govern the sequence chosen for the individual item auctions: (1) Japanese auctions would be conducted for each item, with items sold in random order; (2) Japanese auctions would be conducted for each item, with individual items auctioned in the order from highest expected value to the lowest.

Four institutional features need to be emphasized. First, the auctions for individual items are continuous. There are no rounds or stages in the bidding, so the termination rule is that the auction remains open until only one person is left. Second, the Japanese auction is an ascending-price auction that differs from an ordinary one only in the way that bids are tendered. The price goes up at a pace determined by the auctioneer. All bidders are considered to be "in," that is, agreeing to purchase at the stated price, unless the bidder has explicitly chosen to "drop out." A bidder who has "dropped out" is no longer an active 
bidder on the item and has no standing to buy it, regardless of the final price. The price is determined as soon as only one bidder remains "in." That is, the auction stops when the next to the last bidder "drops out." The person valuing the item most gets it at the value of the bidder with the second-highest bid value.

The third dimension of the rule is the sequence. The items are sold one at a time in order. In one case, the order is randomly determined. In another case, the items are sold in the order beginning with the item with the highest expected value. In the experiment the values of items are randomly drawn with publicly known distributions conditional on the item. Thus, the item for which the expected value is the highest is sold first. In the field there is often common agreement about the items that are likely to bring the highest prices when offered. That feature of common agreement is captured by the experimental procedure.

The fourth dimension of the rule is a sealed bid for a package that is opened before the auction. That is, the results of the sealed-bid auction are to be made public before bidding on the individual items begins. The collection that constitutes the package is designated prior to the auction. If the items, when auctioned individually, do not command prices that total more than the items would bring if sold at the winning sealed bid, then they are sold as a package to the bidder tendering the highest sealed bid. If the items command a sum of prices from the individual auctions that is greater than the sealed bid, then they are sold individually.

\subsection{Rules and Performance}

The overriding question posed for research was related to the efficiency of the allocations fostered by the auction rules. Closely related questions concerned the mechanisms through which the rules operated. What were the sources of any observed inefficiencies? In particular, could packages be efficiently assembled from independent markets, or could bidders for independent components compete successfully against a bid for a package? Who was advantaged or disadvantaged in different architectures? What was the revenue-generating potential of the different rules?

Experiments were conducted with seven and with nine items for auction. Each agent had a private value induced for each of the items offered for auction. In some cases, agents had a superadditive value for a collection of all items. Superadditive means that the value of the collection of all items was greater for the agent than the sum of the values of the items when considered individually. In other cases, agents had superadditive values for a specific collection of three of the items. 
The key feature of parametric configurations was whether the superadditive value for the collection was greater than the sum of the highest (first) values of the items considered independently, or was less. If the superadditive value of the collection is greater than the sum of the first values, then the efficient allocation is that the items should be sold as a package to the agent with the superadditive value. If the sum of the first values is greater than the superadditive value, then the efficient allocation is that items be sold individually. If the auction fails to deliver the items to the hands of the agents valuing them the most, then the efficiency of the auction suffers. An auction that operates at $100 \%$ efficiency has managed to deliver the items exactly to the agents who value them the most.

In order to make data comparable across institutional treatments, the same environmental parameters were conducted in the same sequence of periods for the institutions compared. Thus, subjects in different institutional treatments were exposed to the same sequence of values. Of course, the subjects differed across institutional treatments. If the experiment involved sequential auctions, with items auctioned from highest (expected) value to lowest value, then the agents were informed of the probability distribution from which agent's values were drawn.

Pressures of time and money substantially limited the amounts of experimental data that could be collected. Had the FCC developed a research and funding strategy to facilitate a confident and fully scientific approach, the data would be much richer and decisions would have been made on much more reliable evidence, but that was not the case. The research environment was much more akin to a management situation in which judgments were to be made and having some data is better than having no data. The strategy was to select certain key aspects of the parameter/theory space and collect such data as one could. The experiments were chosen to highlight and explore key points of interaction among competing theories. Exactly how these selections were made and the nature of the statistical arguments that might be made involve detail that cannot be reported here. Because of the limitations on data, the key results are labeled as "observations" and the data are "illustrative," as opposed to the frequently used terminology of "result" and "support."

In spite of the limitations on the number and variety of data, the patterns that do exist in the data are unambiguous. The first observation summarizes the overall pattern by using efficiency comparisons. The auction system efficiency suffers in the presence of a sealed package bid and sequential Japanese auction procedures as compared to the simultaneous auction alternative. 


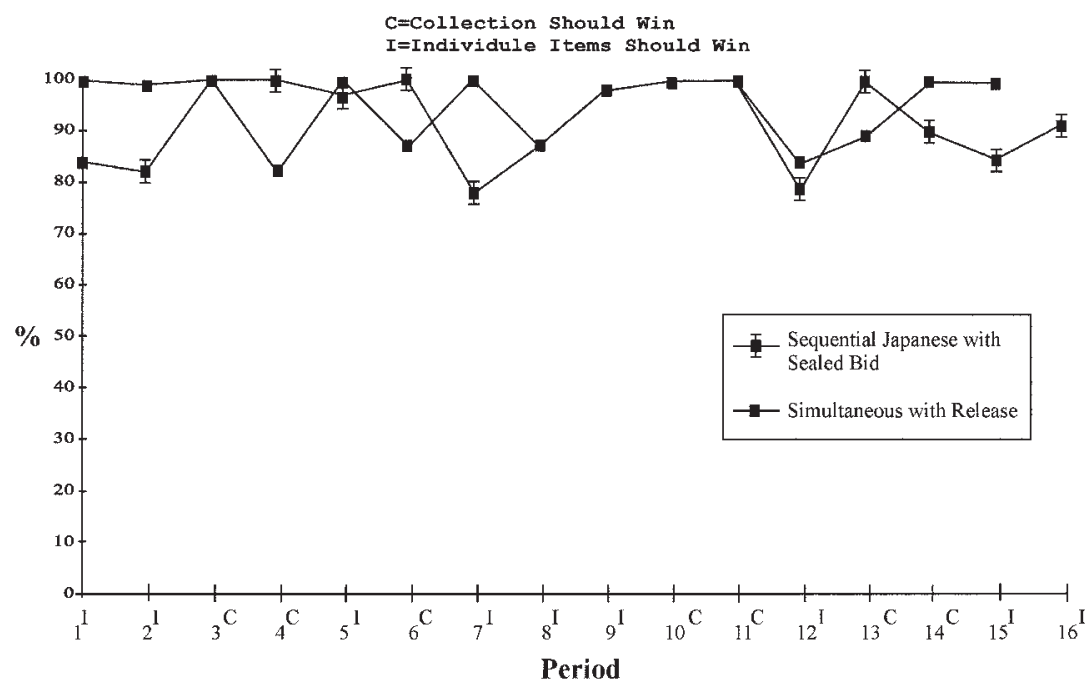

FIGURE 1. EFFICIENCY BY PERIOD: THE SIMULTANEOUS PROCESS HAS AN EFFICIENCY EDGE

Obser vation 1: The overall efficiency of the simultaneous auctions (with a release provision) is higher in all experiments than the Japanese auctions with a sealed bid.

Data illustration. Figure 1 contains a good example of the data. Compared here are two experiments under the same conditions in each period, for a sequence of periods. The individual parameters changed each period, and shown at the bottom of the figure is a notation that indicates if the efficient allocation has items allocated to different individuals (I) or has a collection of items sold to one individual (C). Notice that in twelve out of fifteen periods the efficiency of the simultaneous auctions is at least as high as the Japanese counterpart, and in seven periods the efficiency of the sequential auctions is strictly better. In only three of the fifteen periods is the efficiency of the Japanese auction higher than that of the simultaneous auction with release.

Figure 1 contains hints for additional observations. Notice that the instances in which the efficiency of the Japanese auction exceeds the efficiency of the simultaneous auctions are almost always those in which the sealed-bid package is supposed to win according to the efficient allocation. This suggests that the sealed-bid option creates an advantage for the package. The next result makes that property clear. 
O bs er vation 2: The existence of the package bid option creates an advantage for the agent who wants the collection defined by the package.

Data illustration. Tables I-III contain relevant data. The data are divided into two cases. The first case is one in which the value of the collection to some single agent is greater than the sum of the highest agent values of the items considered individually (and thus should be sold as package to a single agent). The second case is where the maxima of agent values, when considering the items individually, sum to more than the value of the collection to any single agent. In this second case, the items should be sold individually to different agents. Under all conditions studied, when a package bid exists as part of the rules, the collection is sold as a package to a single agent when it should be sold that way, but in about half of the cases in which the items should be sold individually, they are nevertheless sold to the single individual who wants the collection as a package. By comparison, under the other auction rules, in which no package bid is tendered, the collection is

TABLE I.

Seven-Item Experiments with Two Collections of Three Items with Superadditive Val ues ${ }^{\text {a }}$

\begin{tabular}{|c|c|c|c|c|}
\hline & & \multicolumn{2}{|c|}{ Japanese Auction } & \multirow{2}{*}{$\begin{array}{c}\text { Simultaneous } \\
\text { Auction with } \\
\text { Withdrawal } \\
\text { Provision }\end{array}$} \\
\hline & & $\begin{array}{c}\text { Sealed Bid for } \\
\text { Package, } \\
\text { Random Order }\end{array}$ & $\begin{array}{l}\text { No Sealed Bids, } \\
\text { Random Order }\end{array}$ & \\
\hline \multirow{2}{*}{$\begin{array}{l}\text { Value of the } \\
\text { package is } \\
\text { greater than the } \\
\text { sum of the first } \\
\text { values }\end{array}$} & $\begin{array}{c}\text { Collection was } \\
\text { successfully } \\
\text { assembled }\end{array}$ & $\begin{array}{l}2 \text { successes/ } \\
2 \text { periods }\end{array}$ & $\begin{array}{l}2 \text { successes/ } \\
2 \text { periods }\end{array}$ & $\begin{array}{l}5 \text { successes/ } \\
6 \text { periods }\end{array}$ \\
\hline & $\begin{array}{l}\text { Collection } \\
\text { assembled } \\
\text { was } \\
\text { profitable }\end{array}$ & $\begin{array}{l}2 \text { of } 2 \text { assembled } \\
\text { collections } \\
\text { were profitable }\end{array}$ & $\begin{array}{l}1 \text { of } 2 \\
\text { assembled } \\
\text { collections } \\
\text { were } \\
\text { profitable }\end{array}$ & $\begin{array}{l}5 \text { of } 5 \text { assembled } \\
\text { collections } \\
\text { were profitable }\end{array}$ \\
\hline \multirow{2}{*}{$\begin{array}{l}\text { Value of the } \\
\text { package is less } \\
\text { than the sum of } \\
\text { the first values }\end{array}$} & $\begin{array}{c}\text { Collection was } \\
\text { successfully } \\
\text { assembled }\end{array}$ & $\begin{array}{l}5 \text { successes/ } \\
10 \text { periods }\end{array}$ & $\begin{array}{l}0 \text { successes/ } \\
10 \text { periods }\end{array}$ & $\begin{array}{l}0 \text { successes/ } \\
6 \text { periods }\end{array}$ \\
\hline & $\begin{array}{l}\text { Collection } \\
\text { assembled } \\
\text { was } \\
\text { profitable }\end{array}$ & $\begin{array}{l}5 \text { of } 5 \text { assembled } \\
\text { collections } \\
\text { were profitable }\end{array}$ & & \\
\hline
\end{tabular}

a (Number of times event occurred)/(number of times event was possible). 
TABLE II.

$\mathrm{N}$ ine-Item Experiments with Super additive Val ues

for All Nine Items ${ }^{\text {a }}$

\begin{tabular}{|c|c|c|c|c|}
\hline & & \multirow{2}{*}{$\begin{array}{c}\text { Japanese Auction } \\
\text { with Sealed Bid } \\
\text { for Package, } \\
\text { Random Order }\end{array}$} & \multicolumn{2}{|c|}{ Simultaneous Auction } \\
\hline & & & $\begin{array}{l}\text { No Withdrawal } \\
\text { Provision }\end{array}$ & $\begin{array}{l}\text { Withdrawal } \\
\text { Provision }\end{array}$ \\
\hline \multirow{2}{*}{$\begin{array}{l}\text { Value of the } \\
\text { package is } \\
\text { greater than the } \\
\text { sum of the first } \\
\text { values }\end{array}$} & $\begin{array}{c}\text { Collection was } \\
\text { successfully } \\
\text { assembled }\end{array}$ & $\begin{array}{l}2 \text { successes/ } \\
3 \text { periods }\end{array}$ & $\begin{array}{l}4 \text { successes/ } \\
9 \text { periods }\end{array}$ & $\begin{array}{l}3 \text { successes/ } \\
4 \text { periods }\end{array}$ \\
\hline & $\begin{array}{l}\text { Collection } \\
\text { assembled } \\
\text { was } \\
\text { profitable }\end{array}$ & $\begin{array}{l}2 \text { of } 2 \text { assembled } \\
\text { collections } \\
\text { were profitable }\end{array}$ & $\begin{array}{l}2 \text { of } 2 \text { assembled } \\
\text { collections } \\
\text { were profitable }\end{array}$ & $\begin{array}{c}3 \text { of } 3 \text { assembled } \\
\text { collections } \\
\text { were profitable }\end{array}$ \\
\hline \multirow{2}{*}{$\begin{array}{l}\text { Value of the } \\
\text { package is less } \\
\text { than the sum of } \\
\text { the first values }\end{array}$} & $\begin{array}{c}\text { Collection was } \\
\text { successfully } \\
\text { assembled }\end{array}$ & $\begin{array}{l}5 \text { successes/ } \\
15 \text { periods }\end{array}$ & $\begin{array}{l}0 \text { successes/ } \\
8 \text { periods }\end{array}$ & $\begin{array}{l}0 \text { successes/ } \\
3 \text { periods }\end{array}$ \\
\hline & $\begin{array}{l}\text { Collection } \\
\text { assembled } \\
\text { was } \\
\text { profitable }\end{array}$ & $\begin{array}{l}5 \text { of } 5 \text { assembled } \\
\text { collections } \\
\text { were profitable }\end{array}$ & & \\
\hline
\end{tabular}

a (Number of times event occurred)/(number of times event was possible).

never sold as a package when it should not be. The relative advantage of a package bidding process to the agent wanting the package is clear.

Comparative experiments between the simultaneous auctions and sequential Japanese auctions with a package sealed bid yield the properties summarized by the next two observations.

Observation 3: A bidder wanting the package is advantaged by the Japanese auction with a sealed bid for a package, as compared to the same bidder operating under the simultaneous auction rules:

(i) The sealed-bid process always produces an assembled package when one should be assembled, while the simultaneous auctions sometimes fail to produce a successfully purchased collection.

(ii) The sealed-bid process frequently produces an assembled package when it should not produce one, while the simultaneous auction never produces a package when it should not. 
TABLE III.

Nine-Item Experiments with Super additive Val ues for all Nine Items ${ }^{\text {a }}$

\begin{tabular}{|c|c|c|c|}
\hline & & $\begin{array}{c}\text { Japanese Auction } \\
\text { with Sealed Bid } \\
\text { for package, } \\
\text { Ordered by } \\
\text { Expected Values }\end{array}$ & $\begin{array}{l}\text { Simultaneous } \\
\text { Auction with } \\
\text { Withdrawal } \\
\text { Provision }\end{array}$ \\
\hline \multirow{2}{*}{$\begin{array}{l}\text { Value of the } \\
\text { package is } \\
\text { greater than the } \\
\text { sum of the first } \\
\text { values }\end{array}$} & $\begin{array}{l}\text { Collection was } \\
\text { successfully } \\
\text { assembled }\end{array}$ & $\begin{array}{l}7 \text { successes/ } \\
7 \text { periods }\end{array}$ & $\begin{array}{l}4 \text { successes/ } \\
6 \text { periods }{ }^{\mathrm{b}}\end{array}$ \\
\hline & $\begin{array}{l}\text { Collection } \\
\text { assembled } \\
\text { was } \\
\text { profitable }\end{array}$ & $\begin{array}{l}7 \text { of } 7 \text { assembled } \\
\text { collections } \\
\text { were profitable }\end{array}$ & $\begin{array}{l}4 \text { of } 4 \text { assembled } \\
\text { collections } \\
\text { were profitable }\end{array}$ \\
\hline \multirow{2}{*}{$\begin{array}{l}\text { Value of the } \\
\text { package is less } \\
\text { than the sum of } \\
\text { the first values }\end{array}$} & $\begin{array}{l}\text { Collection was } \\
\text { successfully } \\
\text { assembled }\end{array}$ & $\begin{array}{l}6 \text { successes/ } \\
9 \text { periods }\end{array}$ & $\begin{array}{l}0 \text { successes/ } \\
8 \text { periods }\end{array}$ \\
\hline & $\begin{array}{l}\text { Collection } \\
\text { assembled } \\
\text { was } \\
\text { profitable }\end{array}$ & $\begin{array}{c}6 \text { of } 6 \text { assembled } \\
\text { collections } \\
\text { were profitable }\end{array}$ & \\
\hline
\end{tabular}

a (Number of times event occurred)/(number of times event was possible).

$\mathrm{b}$ Two never tried to get the collection.

Data illustration. Tables I-III contain relevant data. In Table I the results of experiments with three item packages are shown. First, consider the sequential Japanese auction with and without a package bid. When it was possible to submit a bid for a package, the package always won when it should have won ( 2 of 2 possibilities) but it also won half of the time when it should not have won (5 of 10 possibilities). The package was always profitable. Consider now a comparison with the simultaneous auction. In the three-item collection experiments, the collection was almost always assembled when it should have been (5 of 6 possibilities) and was never assembled when it should not have been ( 0 of 6 possibilities). In Table II, the nine-item collection was successfully assembled when it should have been in most of the instances under both the Japanese auctions and the simultaneous auctions with the release provision. However, in the cases in which the collection should not have been assembled, it was nevertheless successfully assembled in one-third of the possibilities ( 5 of 15 possibilities) under the 
Japanese auction with the sealed bid, but it was never successfully assembled when it should not have been-when the auction was operating under the simultaneous auction rules.

Obser vation 4: The existence of a sealed bid harms the profits on the items that come late in a sequence of auctions.

Data illustration. Under the sequential auction rules, those that win the early auctions have an incentive to bid up the prices of the items that come later in the sequence. These bidders do not want to win the items, but they do want the prices to be high, so the total of the collection will be above the sealed bid. For example, in a paired experiment of identical parameters, the price of the final item auctioned under the sequential Japanese rules was higher than the same item sold under the simultaneous auction rules (with no package bid) in eight of fifteen periods, while the reverse was true in only three of the fifteen periods. In the remaining four cases, the prices were essentially the same.

The next observation is implicit in the discussion of the observations stated above. It is simply stated without a review of the data.

O bs er vation 5: An order of individual item auctions, from the highestto the lowest-valued items, creates an advantage for the sealed bid.

The final observation explores the sources of inefficiency in the simultaneous auctions that were studied. The data show that the inefficiencies were not so much from a failed attempt at putting together a package, as from a failure to make any attempt at all. Inefficiency was not so much due to the difficulty of coordination, as it was to the perceived risk in the attempt.

O bs er vation 6: Inefficiencies in the simultaneous auctions are due primarily to a failure of the agent with the highest value for the collection to attempt to buy the collection. The release rule reduces the perceived risk of attempting to buy the collection and thereby improves efficiency.

Data illustration. Package assembly, under the parameters studied (a competitive equilibrium exists), is almost always successful when attempted, and successful packages have always been profitable. In the three-item cases the collections were purchased in five of the six instances in which it was efficient to do so, and in the nine-item case it occurred in three of the four times. The most dramatic departure from success was in the seven-item experiments, in which only four attempts were made in seven instances. The power of the release provision is shown by the nine-item experiments in which no release provision 
existed. Without the release provision, in only four of the nine instances in which the collection should have been sold to a single individual did the individual attempt the purchase, and then only two of these attempts were profitable.

The exact behavior of the auctions can be sensitive to very subtle details of how the auction process operates. For example, as is noted in Observations 4 and 5, there is a tendency to drive up the prices of competitors, especially when it may help increase the sum of individual values of a package to exceed the sealed bid on the package. This strategy is risky in that a bidder may end up a winner of unwanted items. In the Japanese auctions, bidders seem to become emboldened when they have information about the number of other bidders that are "in." A bidder seeing several other bidders "in" is willing to stay in "a little longer" - contributing to a type of bubble that drives the price up further than it would have been if information about the number of other bidders had not been present. ${ }^{1}$ Even if the information is not officially available as part of the organized auction, the procedures may be such that it can be inferred. For example, if all bidders are in the same room, and if exit from the auction is accompanied by a click of a key, or a blink of a screen, or any number of other subtle sources of information, such bubbles might exist even when efforts are made to prevent them. The discovery of such phenomena underscores the need to study the operational details of auctions.

Summarizing all observations leads to the following conjecture about the implication of the rules when implemented in environments such as those in the experiments:

1. The simultaneous auctions with release are more efficient than are the Japanese auctions with a sealed bid for the package.

2. The existence of the sealed bid for a package creates an advantage for the agent wanting the collection, and it creates a disadvantage for those wanting items late in the auction sequence (perhaps the smallest agents).

3. Inefficiencies in the simultaneous auctions are primarily due to the fact that agents who would have a collection in the efficient alloca-

1. There seems to be no theoretical foundation for this phenomenon, since expectations of the actions of others could cause the same behavior. Nevertheless, in experiments with the information removed such bubbles were less pronounced if they existed at all. Of course, the numbers of experiments are very small here, so the data can be relied on little more than developing an intuition about what a more complete study would show. 
tion never attempt to assemble the package because of risk aversion. When such agents do attempt to get the collection, they can succeed.

\subsection{Lurking Problems and Al ternative Rul es}

Soon after the Caltech conference, the FCC began to focus on simultaneous auctions with withdrawal provisions as the appropriate set of rules. As the rules began to take form throughout the rulemaking process, the research began to focus on related issues. A primary concern of researchers, but not necessarily the FCC, was the sensitivity of the behavioral characteristics of the auction process to the environment in which it might be operating. While much information had been produced about the general properties of the simultaneous ascending-price auction with a release provision in comparison with other rules involving sequences of auctions, questions remained about how this set of rules might perform in special environments that might reasonably be expected to be present in the circumstances in which the FCC auction would be operating. How were the rules going to perform under the economic environmental circumstances that were thought to exist? Do potential problems exist (in light of nonconvexities, superadditive values, and uncertain common values)? If problems exist, are they generic in the sense that they would almost certainly be encountered, and does the interdependence that they foster promote other types of behavior, such as collusion?

It is well known that nonconvexities and superadditive (complementary) values can destroy the existence of the equilibrium in the competitive model and can also cause instabilities. However, very little is known about what might happen in actual markets with these properties, and during the early stages of rulemaking, nothing was known about the behavior of the particular rules ultimately adopted by the FCC. Figure 2 can be used to demonstrate the nature of some of the lurking problems in a very simple example, which can be applied to both the competitive model and the FCC auction rules.

Suppose the world consisted of four agents with strong complementary tastes for only two units. The essence of complementarity is that values of sets of items are greater than the sum of the items when considered independently. In this case, pairs of licenses have strong complementarities. The complementarity can be seen by the fact that the value of an item depends on whether it is the only item held or is held in the presence of another item. One could say that a special synergy exists for two units, but agents place zero marginal value on the third unit. In the figure the marginal values of each of the four agents 


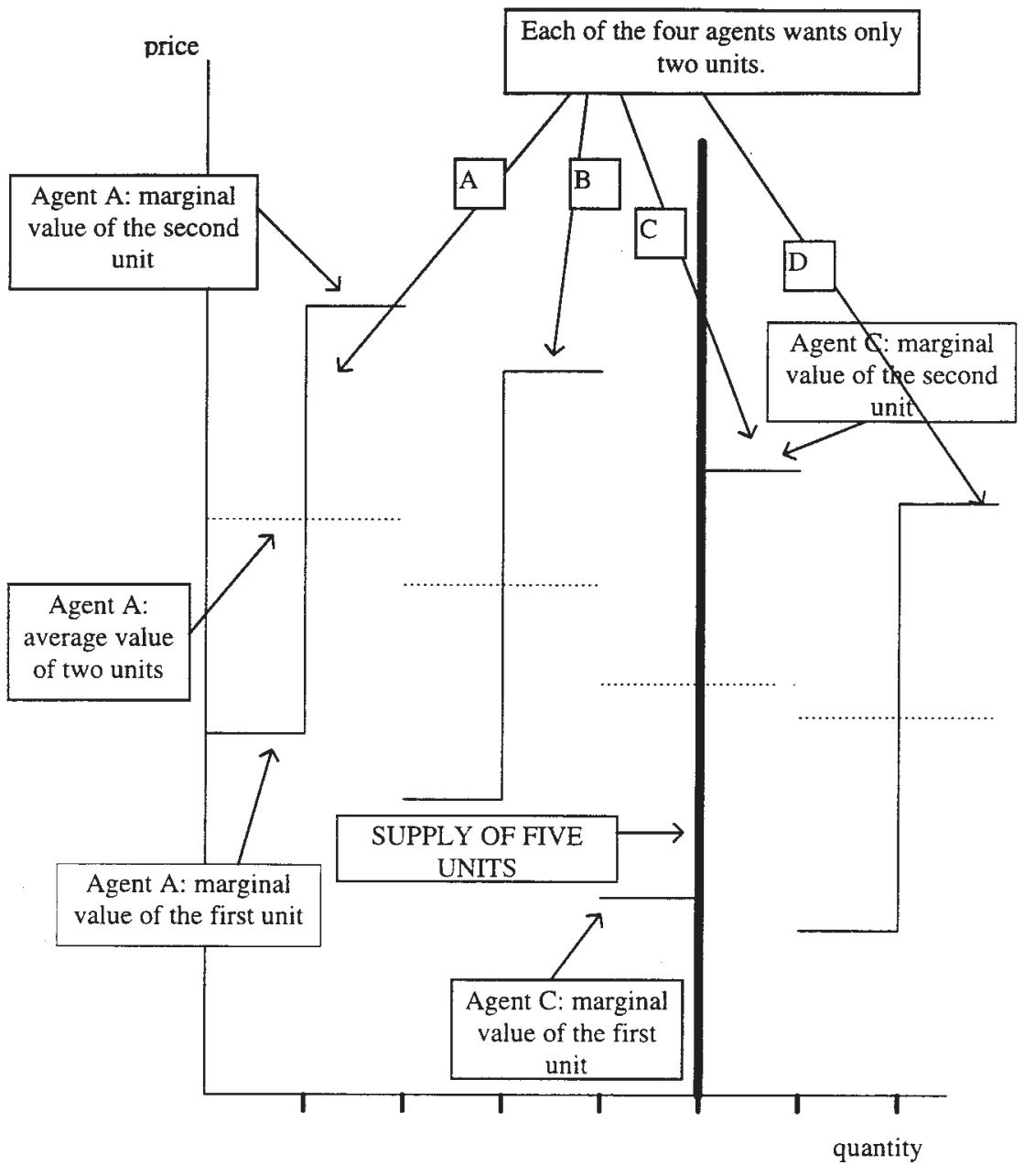

FIGURE 2. SUPERADDITIVE VALUES: COMPETITIVE

EQUILIBRIUM DOES NOT EXIST

are displayed in the order of the average value of two units, starting with the agent with the highest average value, agent $A$, and continuing to the agent with the lowest average value, agent $D$. Only five units are offered for sale.

The example and the similar examples that follow, can be used to make two points: (1) the auction can lead to losses by participants; 
(2) there may be instabilities or "cycles" that delay termination or even prevent the auction from stopping.

In order to develop an intuition about how such phenomena might occur, notice first that no competitive equilibrium exists. There is no price that equates supply with demand. At any price below the average value for agent $C$ (the marginal buyer), demand exceeds supply, and at any price at or above the average value for $C$, supply exceeds demand. The fact that licenses are lumpy creates a nonconvexity in the environment that destroys the existence of that type of equilibrium.

Now, notice that the complementarities create an instability at the margin that has a marginal propensity to push prices up. This property can lead to a loss. Suppose agent $C$ acquires one unit in a simultaneous ascending-bid auction; then, if the agent follows a local, marginal adjustment, (s)he is willing to bid prices up to the marginal value of the second unit. Since all units are identical, there must only be one price in the market, and at the price of the second unit for agent $C$, all agents, including $\mathrm{C}$, lose money. The price is above the average value of all agents. Thus, as one can see, in this environment these rules have a potential, theoretically, for leading bidders into circumstances in which they can suffer a loss even though all "local" decisions are profit-improving to the deciding agent.

If the rules contain a release clause, then theory gives no guide to how the process might stop. If prices ascend to above the average value of any of the agents, then (s)he may want to release the unit to the market and take a certain loss, rather than test the competition into larger regions of loss. When the price is sufficiently low, it could attract a new buyer (such as D) and start the spiral upward again. Thus, from a naive, theoretical point of view, the auction could experience a series of withdrawals over long periods of time and never attain a natural closing within an acceptable time frame. Prices would just cycle.

Experiments demonstrated that the theoretical possibility of losses is also a real possibility. Figure 3 contains the data from an experiment with parameters of the form discussed above. The rules were very similar to those ultimately used by the FCC, except that the auctions were continuous as opposed to involving rounds, and there were no activity rules because of the nature of the stopping rule. A separate market was open for each item, and all markets were simultaneously open. The rule for each market was an ascending-price auction in which any bidder could submit a bid on any item at any time as long as the bid was greater than the previous bid. All markets closed simultaneously when no market showed activity (bids) for some fixed amount of time (e.g., a minute). This stopping rule seemed to eliminate the need for activity rules. Individuals could withdraw or release an item 


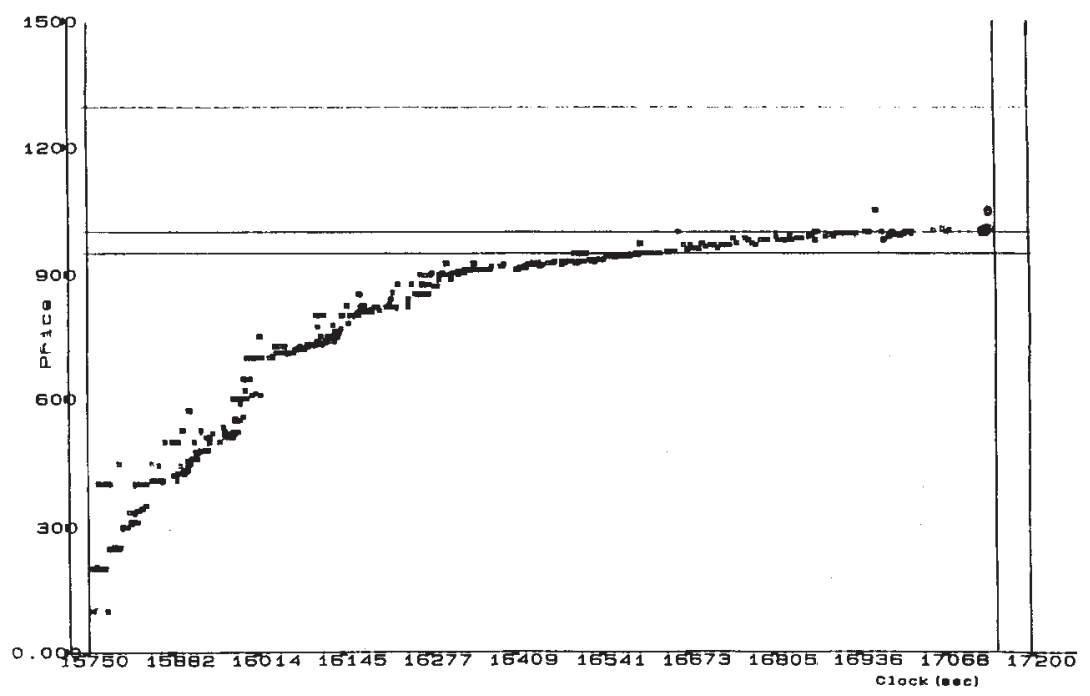

FIGURE 3.

to the market. When a withdrawal occurred, the price was reduced to zero and all bidding started over. If the final price was below the bid that had been made by the withdrawing bidder, the bidder paid the difference.

In Figure 3 the horizontal lines represent some of the important parameters of the experiment. The top horizontal line is the counterpart of the marginal value of the second unit for agent $C$. If the price is bid to the level of the top horizontal line, then losses will certainly occur. The two middle lines are the counterparts of the average value for $C$ and $\mathrm{D}$, respectively. The data represent the bids on all items and the time of submission, measured as the number of seconds that elapsed from the opening of the auction. As can be seen, the time series of bids begins low and continues along what appears to be an exponential path, with some interesting waves, until the auction ends. As is readily observable, the prices of items tend to equate and finally settle near the average value of the marginal agent. Of course, since the marginal agent had a unit at this price, (s)he lost money.

Experiments also demonstrated that the theoretical possibility of cycles is also real. Figure 4 contains data from two additional experiments. Again, the data follow a roughly exponential path toward the average value of the marginal agent. Again, jumps or waves are present. However, in panel A of Figure 4 an item is released. According to the 


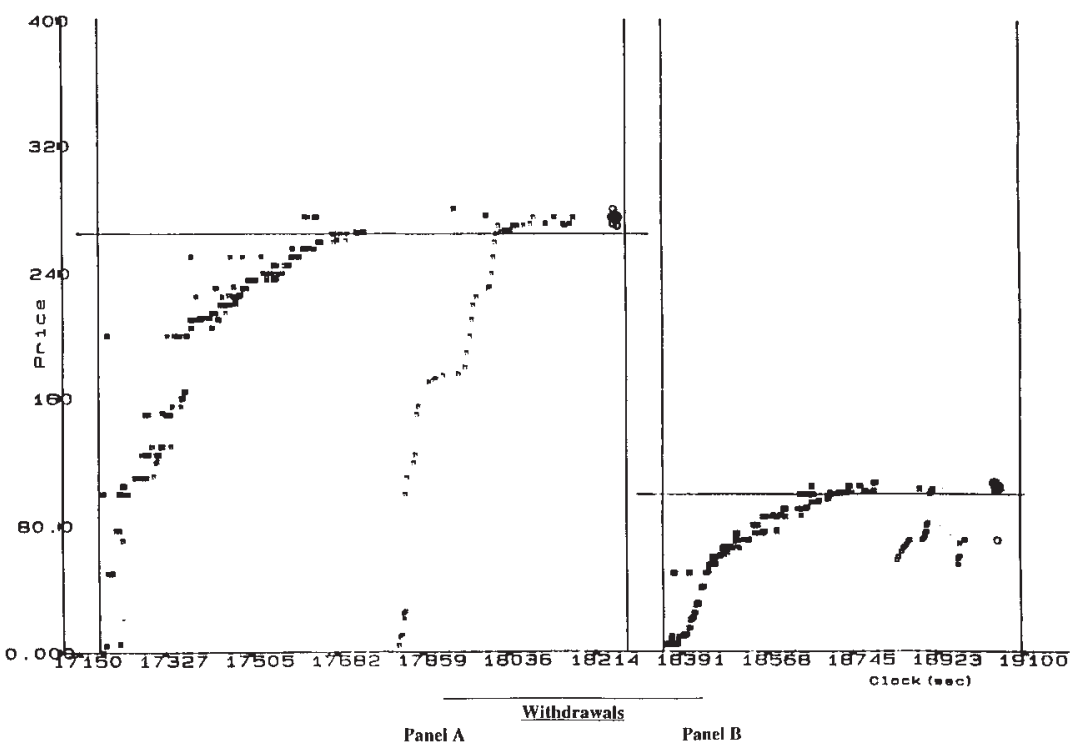

FIGURE 4. WITHDRAWALS

rules of this auction, any released item begins at a price of zero, so a sequence of bids that bring the price of the released items up to the levels of the others is observed. Since the new price of the item is above the average value of the marginal person, the new holder lost money. Panel B shows that releases can occur more than once during an auction. As can be seen in that experiment, the item was released two times, leading to a cycle of length three.

The existence of strong complementarities creates a special kind of competition that does not facilitate efficiency. Complex synergies foster complex fitting problems from which substantial gains are possible. This process of coordination that is necessary for fitting might be accompanied by other activities considered undesirable. If a competitor detects that a rival or two have managed to coordinate their actions so they fit, the firm can damage them both by getting into the bidding action. This is a type of destructive competition in which one agent can make it difficult for a competitor to obtain a package, even when the package represents an efficient allocation. An agent might try to damage others that (s)he views as competitors by driving up the prices, or by acquiring key elements of a package that is of special value to a competitor or to the fit of a group of competitors. Evidence of the ability and the willingness of agents to engage in bidding activities intended 
only to influence the allocations of other agents was contained in Result 4. Further evidence was exhibited in by the willingness of competitors to drive up the price to rivals in the Japanese auction. No systematic evidence exists on the nature of this type of competition. Indeed, we do not understand the role it might play in the allocation process. But, what we do have suggests that it cannot be simply dismissed as implausible.

If selective competition is thought to be a problem, one response might be to shield the identities of the agents. Firms would then be unable to collude and would be unable to identify particular rivals that they would be willing to damage. However, such a response has its difficulties. If a firm is attempting to put together some sort of package, then other firms might be advised to explore packages that fit. Successful fitting would be difficult to achieve by simple random bidding: it requires an understanding of the firm's intentions. Indeed, it might be important to call attention to a coordination problem or to force coordination concessions by tendering bids that could be interpreted as destructive. However, to understand the other firm's strategy, it is necessary to be able to identify that firm through bids. Multiple identification numbers have been suggested in this context. A firm could use some identification numbers to signal intentions where needed and other identification numbers to hide. These complex strategic possibilities have not been explored. We only know that the potential exists and that there might be institutional "fixes."

The final environmental problem stems from the fact that the PCS licenses are thought to have a common but uncertain value. It has been well established experimentally that in such environments a winner's curse phenomenon can exist [for a review of the literature, see Kagel and Roth (1995)]. Each bidder has private information about the common value. If this information is distributed with the true value as a mean, then the highest privately estimated value is greater than the true value. If propensity to bid is positively related to privately estimated value, then the high bidder will be the agent whose private value is the highest above the true value. Unless this property of auctions is recognized, the agent will bid more for the item than its value and as a result suffer a loss from the auction. How this might work out when there is a sequence of bids and complementarities is simply unknown. No experiments have been conducted that provide an assessment of what the dimensions of the problem might be.

In summary, the FCC auction is exploring domains of economic environments about which very little is known: nonconvexities, complementarities, and asymmetric information. The rules of the auction were designed specifically to cope with parts of these environmental 
conditions. The simultaneous nature of the auctions and the withdrawal feature were specifically implemented to facilitate efficient allocations in the presence of such features. Nevertheless, problems are lurking. It is easy to find parameter values at which agents suffer losses, the system cycles, and the results are not even close to $100 \%$ efficient. Does withdrawal help in the very difficult cases, or does it simply lure people into traps in which they can lose money?

Modifications of the simultaneous auctions are still a subject of research. One issue is whether or not the process should be continuous, as opposed to the stages that are now used. Continuous auctions have many advantages. In particular, with continuous auctions there is no obvious need for activity rules and the related complex stopping rules. The stages seem be a response to businesses expressing a need to have time to make decisions, garner the capital for big purchases, and assemble the information needed for bidding. The stages also seem to reflect some doubt about the ability of technology to facilitate a continuous auction.

A lack of confidence in technology, as well as a lack of theory, seemed to dampen enthusiasm for the implementation of a "smart market" that would be capable of dealing with complex bids for packages of licenses. Many experiments have explored the use of package bidding in the context of electronic markets. ${ }^{2}$ Such markets have demonstrated a capability of solving very hard coordination problems. How they might be made to manage common-value problems or destructive competition remains to be determined.

\section{The Devel opment and Implementation of Auction Technology: The Second Stage}

The second stage of applications involved testing the implementation of the specific rules selected to govern the auction. The problems that were addressed stemmed from three sources.

First, the language of lawyers and those writing policy is not precise from the point of view of game theorists, who attempt to model the behavior of the system. Terms that make sense from the point of view of the law can be very imprecise and, depending upon interpretation, could have dramatic effects on the structure of the auction and consequent behavior.

Second, complex systems of rules involve subtle interactions and

2. There are different styles of such markets. For examples see Banks et al. (1989), Brewer and Plott (1996), Plott and Porter (1997), Rassenti et al. (1994), and Rassenti et al. (1982). 
ambiguities. Rules must be internally consistent, and they must be complete in the sense that an outcome is produced by the process under all circumstances. The complex ways in which the rules interact, and the presence of ambiguities, do not become evident until one tries to actually implement the rules in an operational environment. Thus, as part of the research it was necessary to evaluate the consistency and completeness of the rules themselves, as opposed to any assessment of behavior within the context of the rules. A laboratory experiment requires the translation of policy concepts to operational concepts, so the process of experimentation actually produces a working auction prototype.

The third source of problems stemmed from the software and hardware. It was necessary to determine if the software and procedures of the auction successfully implemented the rules, as stated in policy. Even if the rules were complete and consistent in one implementation, they might not be in another. Software implementation and auction procedures must be explored from the point of view of game theory and the strategic opportunities that a real environment fosters.

A group of economists from Caltech ${ }^{3}$ was contracted to test the software and advise on rules and their implementation. Cantor-Fitzgerald was contracted to develop the software for the first narrowband auction in July, 1994. After the July auction, another contractor was selected to develop software for subsequent auctions. Evidently, the FCC wanted to own the software and this was not consistent with the interests of Cantor-Fitzgerald, which used modifications of software that the company uses for market making in the bond industry. The Caltech team was associated with the development and implementation of both technologies.

There are several problems that exist in the many steps between policy conception and operational implementation in the field. First, the exact "rules" were always in a state of evolution. There is a learning that takes place as the rules are implemented. The interactions among rules are subtle. A conflict exists between fairness and proper price discovery, and as this conflict is discovered, there is a tendency for the latter to give way to the former under the pressure of politics. For example, if the auction is taking too long and must be stopped, how should that be accomplished? Many reasonable answers to such questions advanced, such as a single best and final offer, closing specific markets in which no new bids have been tendered, requiring bidders to bid only on items on which they previously bid, etc.

3. They were John Ledyard, Charles Plott, and Dave Porter. 
It was perceived that a person might have special reasons not to want to bid, so waivers were invented, and then automatic waivers were required of the software. The concepts of withdrawals, eligibility, increments, and announcement of stage changes all involve reasonablesounding concepts when considered alone, but there remain questions about how they might interact with each other, with other policies, and with the realities of software performance. Can one waive and bid at the same time? What happens if you withdraw at the end of the auction: should the auction remain open so the withdrawal can be cleared? How shall a withdrawal be priced? How is eligibility of everyone influenced by withdrawals? Should it go up so anyone can buy the item released to the market? How is eligibility influenced by increments: should eligibility be lost if increments are reduced because of lack of bids? As these interactions become discovered, there is a tendency to change the policy.

In the first FCC auctions there was a tendency for policy changes to take place without a full recognition of what they might mean for software development and the time needed for that development and testing, as well as the likelihood that small changes in policy would create a need for further changes that would be discovered only as the implementation advanced. More importantly, the technical complexity and subtleties of game implementation were not fully recognized and reflected in the procedures for communicating with software developers. Moreover, the importance and the technical complexity of the link between policy and rigorous institutional design was not fully appreciated, and that led to problems that were potentially very severe.

When the Caltech team first tested the Cantor-Fitzgerald software, they discovered that Cantor had not been properly informed about the time line within an auction. The contractor was unaware of the existence of rounds. It was also unaware of the time line within a round (that there was a bidding period followed by a computation period that was followed by a withdrawal period, etc., within each round). The policy language was not sufficiently precise to identify exact actions with time. For example, Cantor had been led to believe that phase 3 was a "stay in your own lane" policy in the sense that bidders could only bid on the exact item on which they had been bidding previously. In fact phase 3 required that the number/size of licenses could not be expanded, except possibly by very little. A week before the first auction, the Cantor programming team met with the Caltech team and the FCC. From that meeting a complete reprogramming of the auction software was undertaken according to an architecture that previously had not been communicated to Cantor.

Time pressure before the first auction gave very little opportunity 
to test the Cantor software before the July auction took place. Because of these difficulties, the FCC felt the need to provide a nonelectronic backup system for the July auction. It hired the Caltech team to develop one. This backup was made possible by the fact that all bidders were at the same location, a hotel meeting room. The Caltech experimentalists had practice and experience in implementing such auctions in laboratory environments. To the Caltech group it was simply a bigger experiment than the ones that they had been conducting all along. When implemented during the July auction, the backup system ran in parallel with the Cantor electronic system, which operated successfully. The backup system was just about as fast as the Cantor system, and also operated without flaw.

After the July auction, the FCC contracted with new software developers. The Caltech group agreed to test the new software to make sure the rules were appropriately implemented. However, testing was made very difficult by FCC policies. The FCC adopted a policy of not letting the Caltech team have access to the final software, study (or see) the code, or even talk directly to a software developer. Thus, the auction process was a "black box" from the point of view of the Caltech testers.

The strategy for dealing with the problem of testing was to implement a three-part system. First, the overall strategy adopted by the experimentalists was to use the software as it would be used in an experiment. Preferences were induced by application of standard experimental economics techniques. Subjects then used the software in a series of actual experimental auctions that lasted several days. During these experiments the subjects were at Caltech, but the computers and the FCC auctioneers were in Washington, DC. This methodology facilitated learning derived from user experiences who were engaging the equipment as it would be engaged in practice.

The second part of the strategy was to get problems identified and documented as they were revealed. The heart of the second part of the strategy involved payments (sizable bounties of one hundred dollars or more) to subjects able to find errors in any facet of the auction system. Student subjects from Caltech were trained at the beginning of the summer. They completely understood the details of rules and subtle variations of the rules. The same subjects were used over and over for anything that dealt with software tests. The subjects were paid for keeping notebooks and diaries, so a clear record was maintained about the time and the state of the system when errors were (asserted to be) found. This second procedure allowed us to utilize the special knowledge and skills of this trained subject pool. The subjects explored the rules, the auction setup procedures, and even the user-friendliness of the software. These user bounty procedures are commonly used by 
experimentalists when developing software for laboratory use. From the point of view of the users, the experiments revealed many practical software problems that could have caused serious difficulties if discovered in the field during the FCC auctions. ${ }^{4}$

A third system of checks was a system of "parallel checking." Since the FCC auction software and procedures were used to conduct experiments, the data from the experimental auction were available. These data were fed into a parallel auction software system for computation and comparisons. The parallel system took the raw bid data and from them recomputed all numbers computed by the FCC auction computers. These computations were made during the experiment and afterwards. The parallel system operated from a program that we developed ourselves and for which we were virtually certain that the proper rules and computations had been implemented. All computations made by the FCC programs were rechecked. This method of checking proved valuable in several instances when we were able to reverseengineer the FCC system to identify the source of programming errors. ${ }^{5}$

\section{The Auctions and a Retrospective on Performance: The Third Stage}

The final stage of the research was to provide advice during the operation of the actual FCC auction. Regardless of the amount of preparation and testing, things happen. Behavior might not be as anticipated due to environmental surprises. In spite of testing, rules can be incomplete and policy must sometimes be made on the spot. Decisions must be made on the spot from experience and judgment. During the first auc-

4. Some examples of the types of tests are: What happens if you stay logged on after the initial withdrawal; what happens if you log in from multiple locations at the same time; what happens if you enter 0000 rather than 0 ; what happens if you are theoretically inactive but nevertheless log on after various events; what happens if you log in at the last second of a session or have a power failure; what happens if you follow local software installation exactly to the letter of the instructions? The complaints about friendliness were enough to create enemies: my screen scrolls too fast, too much, too slow; response is too fast, too slow; etc. The test experiments put substantial pressure on the whole FCC auction organization to do rounds quickly, which was important, since the speed of the rounds is a variable that might be used to speed the termination of the overall auction.

5. Important rounding errors were discovered. A miscomputation of eligibility, a type of double counting after a withdrawal, was discovered. Difficulties with eligibility computations after waivers and between phases were checked with this method. The subjects were attempting many unexpected combinations of actions in their attempt to find errors themselves, and this variability in behavior provided an excellent opportunity to check the internal operations of the "black box" that we were given to reverse-engineer. Many bugs were found and corrected, but one can never be positive about software reliability. 
tions, the experimentalists were the only ones that had studied the actual operations of auctions like the one implemented by the FCC. The hope was that the insights that resulted from observing laboratory experiments would be helpful in the field application.

The active participation of the experimentalists during an auction occurred only in the first auction in July 1994. It was here that the procedures for interacting with the bidders and the rules for the realtime operation of the auctions began to take form. An increment committee was formed by the FCC. The job of this committee was to provide policy advice about the minimum allowable bids, the speed of rounds, announcements, the implementation of stages, etc. Plott was a member of the committee, in addition to participating in the backup process.

The experiences gained from laboratory experiments informed the management of the first auction in two ways. Firstly, the experiments had produced many examples of the interaction of procedures, rules, and events that could cause problems in the auction itself, or invite litigation afterwards. Secondly, the patterns of activity in the FCC could be interpreted in the light of the behavior of experiments to gain insights about what was taking place and what might be expected in future rounds.

Laboratory experiments had demonstrated a propensity for agents to misunderstand subtle aspects of the rules. If this happened in the FCC auction, it might be the foundation for a court case. It order to prevent this possibility, during each round the auctioneer made announcements to bidders about critical aspects of the rules, especially those regarding withdrawal and the role of eligibility. Near the end of the auction these general announcements were clearly unnecessary, but those in charge of the auction kept a close eye on agents who might be exhibiting confusion. Help was made available for clarifications of the rules.

The speed of the auction was a general concern. The increment committee was formed to force bids upward and thus speed the process to termination by determining for each license the minimum acceptable bid increment. Very early on, the committee chose to demonstrate a willingness to use no fixed rule. This established the right of the committee to make such judgments, creating some uncertainty on the part of bidders that might be useful for managing the auction, and it provided some flexibility in controls. Some in the FCC thought that a combination of increment rules and stages was sufficient control to speed up the auction and bring it to an efficient termination. A tension existed between the idea that more time to make considered bids, coupled with higher increments on acceptable bids, would speed the auction, and on the other hand, the idea that the termination of the auction should 
be governed primarily by the number of rounds. Thus, one theory would have the auction take more time between rounds, and the other theory would suggest that the rounds be more frequent. Experimental evidence suggested that frequent rounds could be relied upon to generate an efficient and rapid termination. Many of the early experiments that were allowed to terminate naturally involved continuous-time processes without stages. Examination of these data suggested that the FCC auction could go through as many as a hundred rounds. The more rapid the rounds, the sooner would be the termination. Experiments had also produced evidence of the capacity of large increments to be demand-killing: A bidder failing to bid because of a large increment could lose eligibility. If the increment was subsequently reduced, the bidder might not have the eligibility to allow the purchase that (s)he would have otherwise made at the lower price.

Fear of such an event placed the experimentalists in the camp of those against the use of large increment requirements on bids. The possibility of demand-killing policies was very slight as long as the process operated in stage 1 or 2 . However, if stage 3 were implemented, demand killing would be a real possibility. A disagreement existed between those who felt that stage 3 would operate like "brakes" and speed the process to termination, and those who felt that more frequent rounds were a safer way to bring the process to termination.

The first auction was held in a Washington, DC, hotel that the FCC had rented for only a limited amount of time. If the auction failed to terminate within the time frame of the rental, then the whole auction would need to be moved to another location. Because such a move would involve the transfer of equipment and electronic configurations, it involved risks to the smooth functioning of the auction. As the final date approached, support grew for taking the first auction from stage 2 to stage 3 in an attempt to bring it to a close. Plott argued against this change: (1) in stage 3 the possibility of demand-killing increments was the greatest; (2) a possibility of withdrawal existed (recall Fig. 4, panels $\mathrm{A}$ and $\mathrm{B}$, above) and if it occurred, demand killing might result; (3) the software for stage 3 had not been tested (in retrospect there was a bug); (4) the time path of the bids suggested that the process was converging to an orderly termination and that there was only a need to speed the rounds. After consultation with the bidders, the rounds were speeded and stage 3 was never implemented.

As the auction proceeded, there were continued attempts to make judgments about the state of the system and where it might go. What were the patterns that were reminiscent of laboratory auctions? Was there evidence of scalebacks by bidders because of budgets, and were marginal buyers evident? Are there similarities between the laboratory 


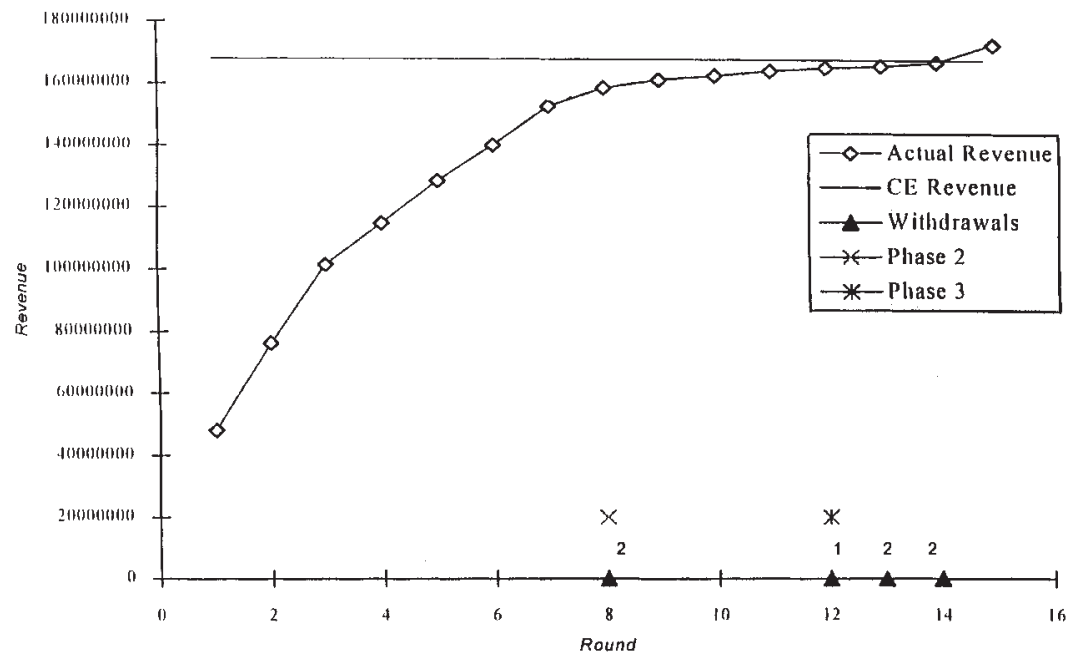

FIGURE 5. TEST, SEPTEMBER 20-26, 1994

market and the FCC auction? If there are similarities, what can we conclude about the FCC auction? The FCC auctions certainly produced a lot of money, but how would one know if they worked to allocate the licenses efficiently? What would the experiments tell us to look for, and under what circumstances should we look? Unfortunately, research has not yet produced good answers. Here we only examine one of the major features of the data.

Experiments exhibit equilibration to predictable magnitudes. Figure 5 reports data from an experiment that was used to test the FCC software prior to the October auction. The parameters chosen for the experiment were similar to those that might exist in the auction, and the general conditions of the experiment were among those that were thought to possibly exist for the actual auction. Thirty licenses were offered in the experiment, exactly as in the October auction.

The demands and supplies are shown in Figure 6. The demand curve for any particular license was derived from the assumption that all other markets were at the competitive equilibrium price and that the agents allocated a fixed budget among licenses to maximize the induced preference. The values of the demand prices are shown above the curve. The units are on the horizontal axis, and the vertical lines are the supplies. A different market demand is shown for each of ten types of licenses. Within a license type the licenses are homogeneous. 


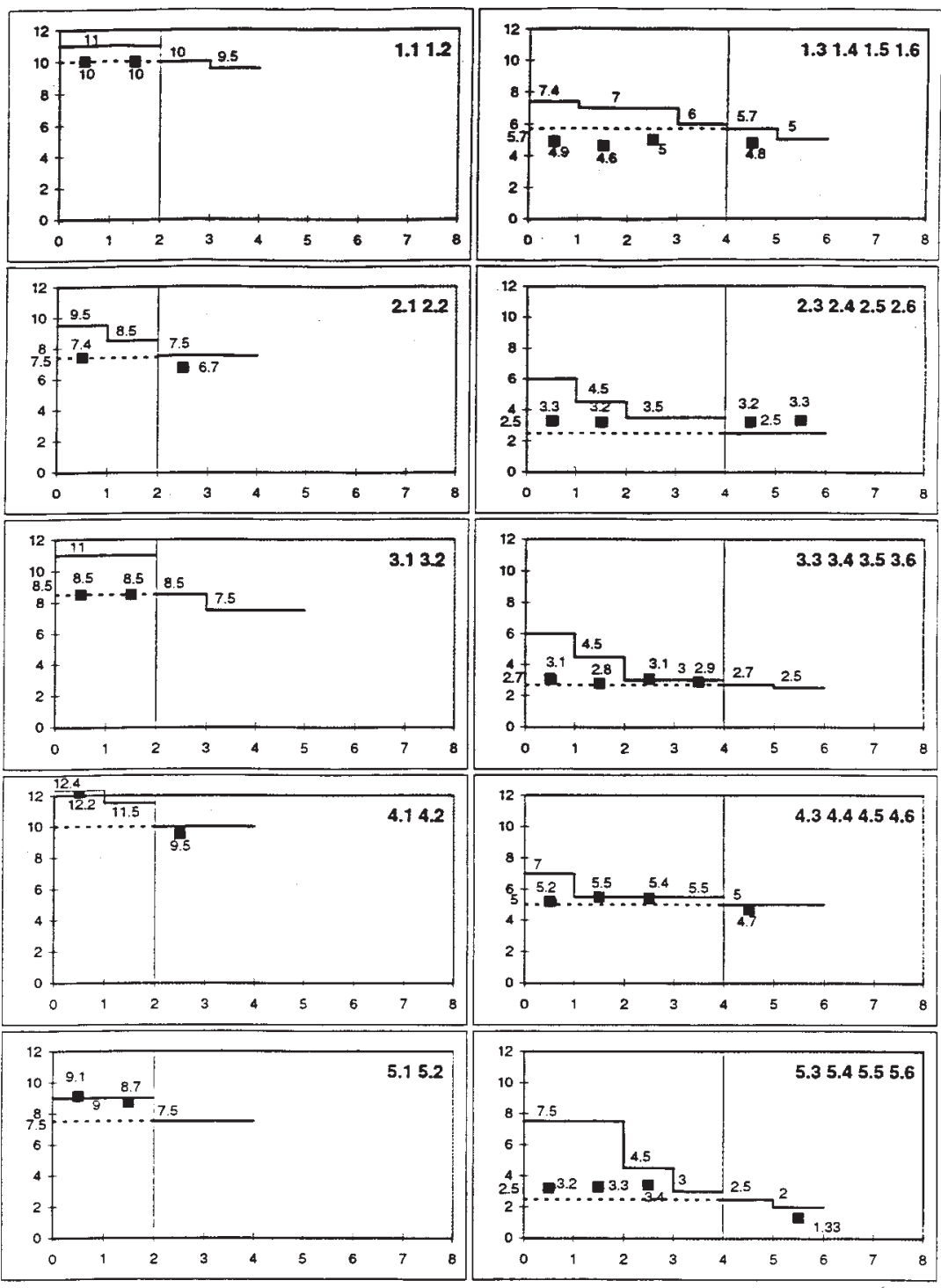

FIGURE 6. 


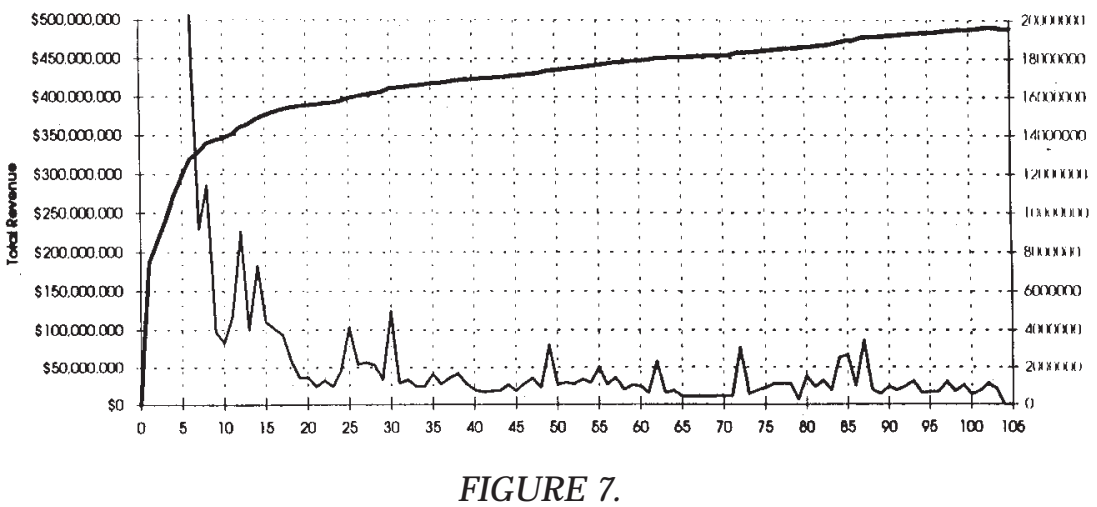

The competitive equilibrium prices are shown as the prices that are at the intersection of the market demand and supply.

The revenues from the experiment are shown in Figure 5. The revenue predicted by the competitive equilibrium model is the horizontal line. As can be seen, the revenue moves upward in a somewhat wavy fashion along what appears to be an exponential path with a jump at the end that is probably caused by an FCC intervention in the experiment. ${ }^{6}$ This experiment, like many others, converges to near the competitive equilibrium.

Figure 7 shows the time path of the revenues generated by the October FCC auction for 30 licenses. As can be seen, there the path has the same qualities of an exponential path and converges. It also has the bumps and waves along the path that are evident in the experimental data. The bottom curve of Figure 7 helps us see the underlying nature of the revenue-generating process. It is a plot of the value of excess bids and shows the adjustments in bidding as relative prices increase. The structure of these changes suggests that the agents operated with budgets, and when prices got so high that the budget would have been exceeded, they scaled back to cheaper items. The FCC auctions seem to have a property of equilibration, and if the principles

6. The FCC phoned during the test experiment and informed us that the test must stop because they needed to move the equipment for a demonstration. The experiment was terminated shortly after that. A second test conducted in October suffered the same fate when the FCC called and informed us that "the next round would be the last." The person in charge had evidently concluded (incorrectly) that the FCC software was working properly. The parallel computation procedure found an error in the FCC software later. 
of their operation are the same as those in the experiments, then the convergence will be near the competitive equilibrium - should it exist.

In Figure 6 the allocations in the experiment are shown as the black squares under the demand curves. The demand curve above the square is the marginal value of the unit to the buyer, and the number next to the square is the price paid for the unit. As can be seen, the prices in the experiment for equivalent items are similar. That is also a property of the FCC auction data. From the experimental allocations, we can also determine that the experimental auctions were relatively efficient. Notice that the units under the demand curve tend to be the ones acquired, and when the units are the external margins and beyond, the ones that they replace are simply the units on the internal margin, so the efficiency loss is not very large. Thus, if the FCC auctions are operating by the same principles, we can conclude that they are fairly efficient.

Thus, the FCC auctions and the laboratory experimental auctions have several qualitative features in common. If indeed the same principles were operating in the FCC environment, then the FCC auction converged to near the competitive equilibrium and exhibited high efficiency.

\section{Concl uding Remarks}

While the use of laboratory experimental methodology is still in its infancy, it seems clear that the value of the techniques was decisively demonstrated in the development of the FCC auctions. The overall success of the auctions must be attributed to others-economic theorists, applied economists, FCC lawyers, and the FCC staff. However, at certain critical junctures, experimental methods supplied data and insights that helped identify and solve problems that could have caused serious damage to the overall auction effort if they had gone undetected. The laboratory methods provided an inexpensive and timely source of data and experience that supplemented the major efforts in the policymaking process. The laboratory methods uncovered problems of a type that could not have been discovered by any other method, except (possibly very expensive) field testing.

It is interesting to compare the FCC auctions with large-scale engineering projects. The rulemaking procedures that the FCC inherits by virtue of being a governmental agency would never be used for engineering decisions. Imagine building a spacecraft with detailed engineering decisions made through the processes dictated by administrative procedures. Yet, in many respects, decisions regarding the detail 
of rules for complex auctions are like engineering decisions. The problems are certainly as complex as those found in engineering projects, and there exist solid theoretical and experimental foundations for making decisions about auction design. The astounding progress that has taken place in basic scientific research in economics has made this application possible. It would seem as though some alternative process should be created for institutional design problems that permit designs to reflect scientific considerations as opposed to political considerations. Nevertheless, in spite of what would seem to be the cumbersome and antiquated procedures dictated by administrative processes, the FCC produced a system that has so far operated effectively. Hopefully, the problems that are known to be lurking and are known to be important within the types of rules the FCC has adopted will not arise in future applications. Objective analysis can be applied, and laboratory testing can be used. Possibly, in the future, the policymaking process can systematically incorporate these scientific advances into decisions.

\section{Ref er ences}

Banks, J.S., J.O. Ledyard, and D.P. Porter, 1989, “Allocating Uncertain and Unresponsive Resources: An Experimental Approach," Rand Journal of Economics 20(1), 1-25.

Brewer, P.J. and C.R. Plott, 1996, "A Binary Conflict Ascending Price (BICAP) Mechanism for the Decentralized Allocation of the Right to Use Railroad Tracks," International Journal of Industrial Organization, 14, 857-886.

Kagel, J.H. and A.E. Roth, eds., 1995, The Handbook of Experimental Economics, Princeton University Press.

Plott, C.R. and D.P. Porter, 1996, "Market Architectures and Institutional Testbedding: An Experiment with Space Station Pricing Policies," Journal of Economic Behavior and Organization, 31, 237-272.

Rassenti, S.J., V.L. Smith, and R.L. Bulfin, 1982, "A Combinational Auction Mechanism for Airport Time Slot Allocation," Bell Journal of Economics, 13(2), 402-417.

— S.J., S.S. Reynolds, and V.L. Smith, 1994, "Cotenancy and Competition in an Experimental Auction Market for Natural Gas Pipeline Networks," Economic Theory, 4, $41-65$. 